\title{
Natural rarity places clownfish colour morphs at risk of targeted and opportunistic exploitation in a marine aquarium fishery
}

\author{
Thane A. Militz ${ }^{1, *}$, Simon Foale ${ }^{2}$, Jeff Kinch $^{3}$ and Paul C. Southgate ${ }^{1}$ \\ ${ }^{1}$ Australian Centre for Pacific Islands Research and Faculty of Science, Health, Education and Engineering, University of the Sunshine \\ Coast, Maroochydore, Australia \\ 2 College of Arts, Society and Education, James Cook University, Townsville, Australia \\ ${ }^{3}$ National Fisheries College, National Fisheries Authority, Kavieng, Papua New Guinea
}

Received 14 February 2017 / Accepted 25 May 2018

Handling Editor: Richard Lorne Little

\begin{abstract}
As fish stocks become depleted, exploitation eventually fails to be cost-efficient. However, species or morphs of species can suffer from continual exploitation if their rarity results in increased value, justifying the cost-efficiency of targeted or opportunistic exploitation. The trade in coral reef fishes for public and private aquaria is an industry in which naturally rare species and rare morphs of species command high prices. Here we investigate the relationship between price and the natural prevalence of colour morphs of two highly demanded clownfish species using a localised case study. The export prices for colour morphs increased with decreasing prevalence of occurrence $\left(y=4.60 \mathrm{x}^{-0.51}, R^{2}=0.43\right)$, but price increase was inversely less than the observed reduction in prevalence. This renders rare colour morphs (i.e., those at relatively low prevalence) at risk of opportunistic exploitation. Using ecological data, we also demonstrate how this increased value can subject rare colour morphs with aggregated distributions to targeted exploitation. These findings are discussed in relation to the broader marine aquarium trade, identifying taxa potentially at risk from exploitation motivated by rarity and addressing potential management strategies.
\end{abstract}

Keywords: Aquarium trade / Amphiprion percula / Premnas biaculeatus / Papua New Guinea / management / consumer demand

\section{Introduction}

Exploitation of live organisms is a potential threat to biodiversity and ecosystem resilience (Rosser and Mainka 2002; Bellwood et al., 2004), with numerous extinction pathways attributed to exploitation (Clark, 1973; Dulvy et al., 2003; Courchamp et al., 2006; Branch et al., 2013). This may seem paradoxical as basic economic theory suggests that the point at which it is no longer economically efficient to exploit a species will precede ecological extinction (Courchamp et al., 2006; Grafton et al., 2007). As population abundance decreases it becomes more difficult, and therefore more costly, to exploit the remainder of the population. Where cost of exploitation exceeds the financial return, exploitation generally stops until a point in time when the species has recovered in abundance to make exploitation cost-effective again. However, naturally less abundant species or morphs of species could suffer from continual exploitation if this rarity

*Corresponding author: tmilitz@usc.edu. au makes them more attractive to consumers (Courchamp et al., 2006; Hall et al., 2008).

The trade of wild coral reef fishes for public and private aquaria ownership is an expanding industry worldwide (Wabnitz et al., 2003; Leal et al., 2016). Consumer demand exists for particular species known to be suited to life in captivity and deemed to be aesthetically pleasing (Murray and Watson, 2014; Militz et al., 2017). A segment of the marketplace also ascribes importance to the rarity of traded fishes (Militz et al., 2017), and price premiums are associated with both the natural and perceived rarity of species and morphs of species (Dulvy et al., 2003; Rhyne et al., 2012a).

To satisfy consumer demand, marine aquarium fisheries operate in a manner that promotes targeted exploitation (Branch et al., 2013; Militz et al., 2018b). Fishers generally target a limited range of species in comparison to the available biodiversity (Stevenson et al., 2011; Militz et al., 2018b). This selectivity is best demonstrated by the limited number of species that comprise the bulk of organisms exported from nearly all source countries supplying the trade (Wabnitz et al., 2003; Rhyne et al., 2012b). Targeted exploitation is not 


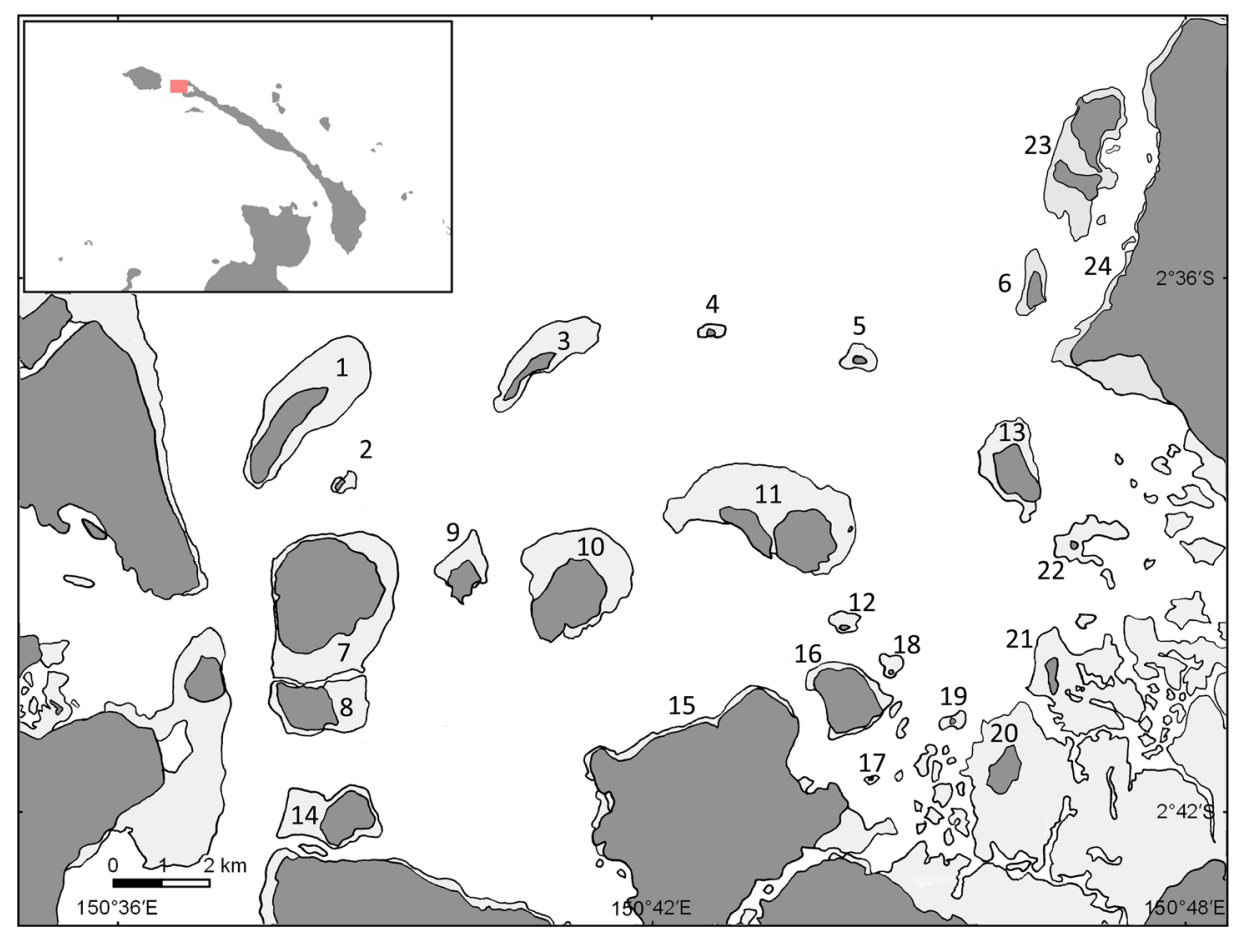

Fig. 1. Map of the Kavieng lagoonal system where numbering identifies surveyed reefs. The white areas indicate water, the dark shaded areas represent land, and the light shaded areas indicate areas with reef development. Top left insert places the lagoonal system (red highlight) in geographical context within New Ireland Province, Papua New Guinea.

restricted to abundant species and may extend to rare species if their value exceeds the bioeconomic equilibrium (Gordon, 1954), when profitability is similar among alternative targets.

Even if the value of rare taxa is below the bioeconomic equilibrium, exploitation may still occur opportunistically if the rare taxa have relatively higher value and overlap in distribution with targeted taxa. This mode of opportunistic exploitation allows for continued exploitation of rare taxa past the point at which targeted exploitation would no longer remain economically efficient (Branch et al., 2013). Evidence of opportunistic exploitation among small-scale tropical fisheries (Purcell et al., 2013; Branch et al., 2013) would suggest this fishing strategy to be employed within marine aquarium fisheries.

Resource managers must recognise scarce taxa at risk from targeted and opportunistic exploitation given already small population sizes predispose such taxa to local and/or global extinctions (Dulvy et al., 2003). There is particular interest in evaluating the potential for rare morphs of commonly traded taxa to be at risk, given that cryptic species are frequently traded prior to scientific evaluation (e.g., Tea and Gill, 2016) and disproportionate exploitation of morphs could have negative repercussions for genetic diversity within populations (Drew et al., 2008, 2010; Madduppa et al., 2018).

For this reason, our study combines economic and ecological data to evaluate whether colour morphs of two fish species commonly exploited for the marine aquarium trade could be at risk from targeted and/or opportunistic exploitation. This is done using the marine aquarium fishery of Papua New Guinea (PNG) as a case study. Our evaluation extends into discussion of intervention strategies for the marine aquarium trade that seek to minimise the desirability of rare taxa from having negative repercussions on resource sustainability.

\section{Material and methods}

Two licensed companies engaged in the collection and export of marine aquarium fishes within PNG between 2008 and 2012, with only a single export company operating at any point in time. As a condition of export licensing, export invoices were lodged with the National Fisheries Authority of PNG. Export invoices itemised the export price of individual fishes and the invoices used in our study, dated from 2011 to 2012, also differentiated the sale of colour morphs of two species of clownfishes (Pomacentridae), Amphiprion percula and Premnas biaculeatus. Morphs of A. percula were categorised as regular, melanistic, or aberrant while morphs of $P$. biaculeatus could be grouped as regular or aberrant. Melanistic morphs refer to melanin-induced pigmentation that darkens the fish's body (Militz et al., 2016b) while aberrant morphs refer to variations in stripe patterning that include the addition or absence of stripes (Allen, 1972; Fautin and Allen, 1997). The export prices of the colour morphs of each species were independently compared using one- and two-sample $t$-tests in the $R$ statistical software (R Core Team, 2017).

Natural clownfish populations were assessed for morph prevalence within the Kavieng lagoonal system of New Ireland Province, PNG (Fig. 1) as per Militz et al., (2016b). This site was chosen on the basis that it had no prior history of exploitation for the marine aquarium trade and is a proposed 
site for future aquarium fishery operations within the country (Dandava-Oli et al., 2013). The lagoonal system also reflects a high level of habitat diversity (Hamilton et al., 2009), making it an ideal location for evaluating habitat dependency in marine taxa (Militz et al., 2015; Militz et al., 2016b). Populations of $A$. percula and $P$. biaculeatus were assessed over a cumulative $50 \mathrm{~km}$ of shallow-water habitat within the lagoonal system. Where the target species were observed, individual fish were classified according to which morph category best described them, using the definitions provided by Militz et al., (2016b) to differentiate melanistic morphs. Personnel previously active in the PNG aquarium fishery confirmed the definitions were comparable to commercial morph categories used by the fishery. The population frequencies of the different morph categories were compared using two-proportions $z$-tests in $R$ (R Core Team, 2017). Unbiased recursive partitioning using the ctree function in the $R$ package partykit (Hothorn and Zeileis, 2015) was conducted to determine if variation among reefs, surrounding habitats (fine sediment, loose rubble, solid rock, and live coral), or depth were spatial predictors of morph prevalence.

Export price as a function of relative morph prevalence and species was fitted to an exponential function by $\log _{10}$ transforming both the response and predictor variables in the model before use of a linear model in $R$ ( $\mathrm{R}$ Core Team, 2017). A single exponential function sufficiently explained $\left(R^{2}=0.43\right)$ the relationship of export price as a function of the relative morph prevalence of both species, as the slope $(P=0.45)$ and intercept $(P=0.07)$ terms of the model were not significantly different between species. The exponential function representing the bioeconomic equilibrium for populations of $A$. percula and $P$. biaculeatus retained the same intercept as our modelled relationship, but the slope was adjusted to assume inverse proportionality (Gordon, 1954). All prices are reported as 2012 U.S. dollars, without correcting for inflation.

\section{Results}

Export invoices showed a total of 10329 individual fishes exported for the marine aquarium trade from PNG during the study period, with $99.1 \%$ identified to species level. Amphiprion percula and P. biaculeatus were amongst the first $(n=3166)$ and ninth $(n=145)$ most exported species, respectively, together accounting for $32.1 \%$ of exports. Prior research indicates both species were heavily targeted by the marine aquarium fishery, with respect to the available biodiversity (Militz et al., 2018b). Sales of melanistic and aberrant $A$. percula morphs accounted for $3.5 \%$ of the fishery's exports by value and $1.8 \%$ of exports by quantity $\left(\chi^{2}=79.8\right.$, $P<0.01$ ). Aberrant $P$. biaculeatus morphs contributed to $1.4 \%$ of the fishery's exports by value and $0.3 \%$ of exports by quantity $\left(\chi^{2}=82.6, P<0.01\right)$.

Only a single aberrant $A$. percula morph was reported on export invoices with a price of $\$ 30.00$, which was several times greater than the mean export price of regular $A$. percula $\left(\$ 5.36 \pm 0.02 ; t_{(2,2979)}=1127.67, P<0.01\right)$. The mean export price of melanistic $A$. percula morphs was also significantly higher $(\$ 11.03 \pm 0.34)$ than the price of regular morphs $\left(t_{(2,185)}=16.81, P<0.01\right)$. The mean export price of aberrant
P. biaculeatus morphs was more than five times higher $(\$ 23.78 \pm 5.30)$ than for regular morphs $\left(\$ 4.66 \pm 0.09 ; t_{(2,35)}=\right.$ 3.61, $P<0.01)$. The export prices of two aberrant $P$. biaculeatus morphs (\$150.00 each) rendered these individual fish the highest value export from the PNG marine aquarium fishery.

Relative morph prevalence was assessed within the Kavieng lagoonal system with a sample size of 1,068 for $A$. percula and 1,343 for $P$. biaculeatus. Aberrant $A$. percula morphs were found to account for $2.3 \%$ of fish in the surveyed population, being less frequently encountered than melanistic morphs $\left(19.7 \% ; \chi^{2}=161.9, P<0.01\right)$ and regular morphs $\left(78.0 \% ; \chi^{2}=1936.9, P<0.01\right)$. Unbiased recursive partitioning was unable to detect any significant variation in relative aberrant morph prevalence across the surveyed spatial scales $(P>0.05)$.

Melanistic A. percula morphs (19.7\% of the $A$. percula population) were also less frequently encountered than regular morphs $\left(78.0 \% ; \chi^{2}=1336.4, P<0.01\right)$. Melanistic morphs were unevenly distributed within the population, showing significant variation among reefs, water depths, and surrounding habitats (Fig. 2). Melanistic morphs were most frequently observed in shallow water habitats of the lagoon's interior (Node 7, Fig. 2) where a cluster of five reefs (reefs 16, 17, 19, 20 , and 21 in Fig. 1) accounted for $53.3 \%(n=210)$ of all melanistic morphs surveyed within the lagoonal system. Within the shallow water habitats, melanistic morphs were more frequently associated with rocky or fine sediment habitats (Node 10, Fig. 2).

Aberrant morphs of $P$. biaculeatus were less frequently encountered (7.3\% of the $P$. biaculeatus population) than regular morphs of the species $\left(92.7 \% ; \chi^{2}=1955.8, P<0.01\right)$. Unbiased recursive partition was unable to detect any significant variation in relative aberrant morph prevalence across the surveyed spatial scales $(P>0.05)$.

There was an inverse relationship between export price and relative morph prevalence $\left(y=4.60 \mathrm{x}^{-0.51}, R^{2}=0.43\right)$, but the increase in export price was inversely less than the observed reduction in relative morph prevalence (Fig. 3). Only 12 individual fishes (two aberrant $P$. biaculeatus and ten melanistic $A$. percula), representing $5.4 \%$ of the trade in rare morphs $(n=222)$, had export prices in excess of prices based on the bioeconomic equilibrium (Fig. 3 ).

\section{Discussion}

With the potential for high reward, fishers and exporters are incentivised to exploit melanistic and aberrant $A$. percula and $P$. biaculeatus morphs for the aquarium trade. Our results show export prices increased exponentially with increasing morph rarity for two species of clownfishes. However, the value prescribed to the studied morphs does not reflect an exaggerated value of rarity (Courchamp et al., 2006; Hall et al., 2008), as the increase in value did not exceed the increase in rarity. This could be taken as evidence that the studied morphs face a reduced likelihood of targeted exploitation in the PNG marine aquarium fishery (Branch et al., 2013), assuming fishers behave as rational actors (Kahneman and Tversky, 1979). On the basis of random encounters, opportunistic exploitation of the rare clownfish 


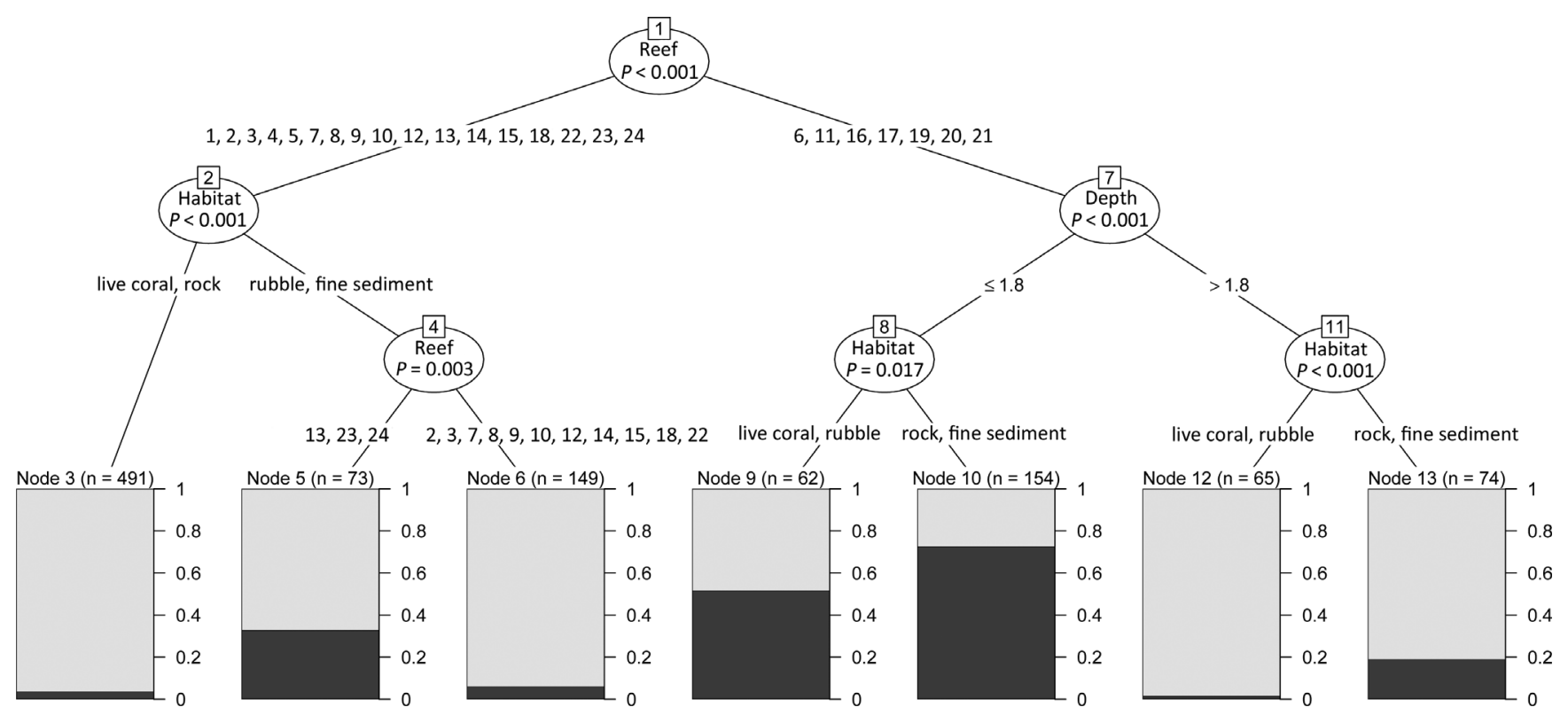

Fig. 2. Unbiased recursive partitioning of spatial scale variables predicting the distribution of melanistic and regular $A$. percula morphs within the Kavieng lagoonal system. Dark shading indicates the proportion of melanistic individuals and light shading indicates the proportion of regular individuals at each terminal node. Reef identification numbers correspond to Figure 1.

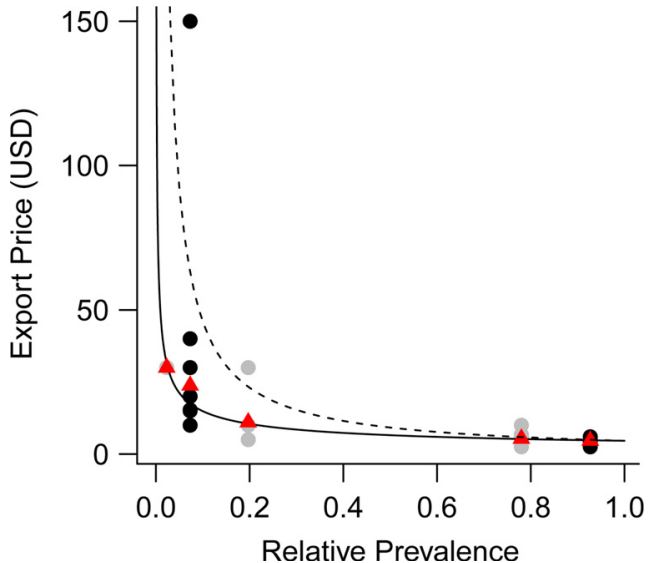

Fig. 3. The mean export price (red triangles) and export price data of the different $A$. percula (grey circles) and P. biaculeatus (black circles) colour morphs with respect to their relative prevalence in the Kavieng lagoonal system. The solid line represents the exponential equation $\left(y=4.60 \mathrm{x}^{-0.51}\right)$ best describing export price as a function of relative morph prevalence. The dashed line represents the bioeconomic equilibrium, if export prices were inversely proportional to relative morph prevalence $\left(y=4.60 \mathrm{x}^{-1.00}\right)$.

morphs would be a more economically efficient fishing strategy.

This notion holds true for aberrant morphs of both $A$. percula and $P$. biaculeatus which were randomly distributed among their populations across the surveyed spatial scales. Given the random distributions, there is limited scope for fisher knowledge, skill, or gear investment to improve capacity in targeting these portions of the clownfishes' populations. The combination of economic and ecological qualities characterising aberrant $A$. percula and $P$. biaculeatus morphs reduces the scope for these morphs to be at risk of targeted exploitation (Courchamp et al., 2006; Branch et al., 2013). This does not preclude risk-seeking fishers (Kahneman and Tversky, 1979) from irrationally targeting these morphs, but we note risk-seeking behaviours in small-scale fisheries typically characterise only a minority of fishers (Eggert and Lokina, 2007). Rather, the economic and ecological qualities of aberrant $A$. percula and P. biaculeatus morphs are more characteristic of taxa at risk from opportunistic exploitation (Branch et al., 2013). In the case of aberrant P. biaculeatus morphs, opportunistic exploitation could extend beyond active aquarium fishers to even fishers engaged in subsistence food fishing. Our evidence for this comes from prior export enterprises using mobile phone text-messaging to alert the general populace of cash rewards for the capture of aberrant $P$. biaculeatus morphs (authors pers. obs.).

The non-random spatial distribution of melanistic $A$. percula morphs, in contrast, revealed several locations where melanistic morphs occurred at relatively high prevalence. The prevalence of occurrence in shallow water habitats of reefs in the lagoon's interior would justify the economic efficiency of targeted exploitation for fishers with the knowledge and capability to access these concentrations of melanistic $A$. percula morphs. This would put more than half of the regional melanistic morph population at risk of targeted exploitation (i. e., those individuals within the locational concentration), while the remainder of the population would be at risk from opportunistic exploitation given the relative high value of this morph.

The adoption of both targeted and opportunistic exploitation strategies by fishers can lead to the unsustainable harvest of taxa (Courchamp et al., 2006; Branch et al., 2013). However, the absence of exaggerated value for rarity among 
the studied morphs would limit targeted exploitation to the locational concentration of melanistic $A$. percula morphs, and limit depletion to the point of bioeconomic equilibrium (Grafton et al., 2007; Branch et al., 2013). Beyond this, opportunistic exploitation is more likely to be a concern for the PNG fishery. Concern for the unregulated exploitation of aberrant $A$. percula morphs arises from some aberrant individuals having shown noticeable genetic differentiation from other individuals of the species (Litsios et al., 2014). Melanism in clownfishes has also been linked to genetic differences for at least one species (Amphiprion clarkii), but presently it is unclear whether colouration alone explains such differences (Litsios et al., 2014; Militz et al., 2016b).

In addition to concern for a loss of biodiversity, there is value in sustaining rare colour morphs as an economically valuable resource for marine aquarium fisheries. In the PNG fishery, melanistic and aberrant morphs of $A$. percula and $P$. biaculeatus accounted for $4.9 \%$ of the fishery's export value. Globally, both $A$. percula and P. biaculeatus are important commodities in the marine aquarium trade being among the 20 most frequently traded species, and are exported from a number of countries (Wabnitz et al., 2003; Rhyne et al., 2012b). Melanistic and aberrant morphs of $A$. percula and $P$. biaculeatus are known to exist from several other locations, beyond PNG (Allen, 1972; Fautin and Allen, 1997). Given the potential for clownfishes to experience targeted exploitation in other regions (Shuman et al., 2005; Madduppa et al., 2014), opportunistic exploitation of rare morphs likely occurs elsewhere.

Comparative studies evaluating relationships between the natural rarity of taxa and their exploitation are lacking for the marine aquarium trade. We intend for this article to bring a new perspective to how exploitation for the marine aquarium trade targets not only species (Stevenson et al., 2011; Militz et al., $2018 \mathrm{~b}$ ), but potentially morphs of species as a consequence of increased value being associated with natural rarity. There are numerous polymorphic reef fishes, with a multitude of explanatory factors giving rise to polymorphism. Exploitation of sex-associated (Kodric-Brown 1998), dietary induced (Whitman et al., 2007), or environmentally elastic morphs (Cortesi et al., 2015) is less of a potential concern than exploitation of naturally rare morphs with a genetic basis (Drew et al., 2008, 2010; Litsios et al., 2014). Exploitation of the latter has potential to extirpate the resource and reduce genetic diversity of populations (Madduppa et al., 2018).

Useful policy in managing the exploitation of rare taxa involves trade restrictions and shortlists of allowed exports (Courchamp et al., 2006; Branch et al., 2013). For example, PNG has implemented export bans on seven species of birdwing butterflies, as a consequence of their rarity and the global demand from insect collectors (Slone et al., 1997). For the developing marine aquarium industry, shortlists of allowed species and morphs may be more advantageous than imposing bans, as bans are reactionary management that may come too late to avoid depletion of naturally rare taxa (Branch et al., 2013). Shortlists of allowed species and morphs can be coupled with collection limits for further management (Saleem and Islam, 2008; Dee et al., 2014), but trade limits are unlikely to be effective given that disparities between collection and trade can be substantial (Militz et al., 2016a, 2018a). Alternatively, spatially restricting extractive exploitation, as practiced in the PNG fishery previously (Militz et al., 2016a, $2018 \mathrm{a}, 2018 \mathrm{~b}$ ), or the establishment of marine reserves could limit the spatial extent over which opportunistic exploitation occurs (Branch et al., 2013). However, the effectiveness of these policy ideas for mitigating the risks of targeted and opportunistic exploitation is inherently limited without effective monitoring and enforcement (Militz et al., 2018b).

The harsh reality is that many of the source countries supplying the marine aquarium trade (Wabnitz et al., 2003; Rhyne et al., 2012b; Leal et al., 2016) are economically marginalised and with minimal fishery regulations (Dee et al., 2014). Where regulations do exist, the capacity for enforcement is usually low (Erdmann, 2001; Militz et al., 2018b). This greatly limits the ability of many countries supplying the marine aquarium trade to adequately protect exploited taxa. The marine aquarium trade's contribution to the endangerment of the Bangaii Cardinalfish, Pteragogon kauderni, being a noteworthy example (Vagelli, 2008). For these reasons, we suggest management strategies aiming to reduce consumer demand are likely to be a more effective solution.

Conservation interventions appealing to consumer ethics are likely to be the most effective method in reducing demand for naturally rare taxa in the aquarium trade. Trade surveys reveal consumers desire more information at the point of sale (Murray and Watson, 2014) with consumers indicating preferences for environmentally sustainable livestock collection and supply (Militz et al., 2017). Awareness campaigns portraying the natural rarity of taxa being exploited for the aquarium trade may be successful in this regard. While it can be argued that publishing information on species abundance in the public domain could contribute to rarity-motivated consumption (Hall et al., 2008; Militz and Foale, 2017), the importance consumers ascribed to rarity was less prominent than the importance ascribed to environmental sustainability (Militz et al., 2017). Thus, consumer understanding of sustainability risks associated with the exploitation of naturally rare taxa may help curb demand.

An additional management strategy would be to present acceptable alternatives to consumers. Rarity in the marine aquarium trade is largely a product of a skewed and scaledependent human perspective: a species may be considered rare when portrayed as such by digital media and suppliers, rarely encountered due to difficulties in accessing habitat (i.e., deep-water species), infrequently collected due to limited demand or intolerant of captive conditions (i.e., corallivorous butterflyfish), geographically restricted (i.e., island endemics), or widespread but at low densities (Hall et al., 2008; Rhyne et al., 2012a; Militz and Foale, 2017). Consumption of only the latter two perceptions of rarity poses risks to the exploited species and exploitation for the aquarium trade has been directly linked to extinction risks for geographically restricted species (e.g., Pteragogon kauderni) and reduced abundances of widespread species at low densities (e.g., Amphiprion ocellaris) in some regions (Shuman et al., 2005; Vagelli, 2008; Madduppa et al., 2014). Industry and social media promotion of naturally abundant, but rarely traded taxa would offer an alternative avenue by which consumers could obtain "rare" taxa that poses a much lower risk to the exploited population.

In the case of rare clownfish morphs, sustainable alternatives such as aquacultural supply could mitigate demand for taxa derived from wild populations (Militz, in press). 
However, aquaculture development in the marine aquarium sector is far from commercially producing the full range of taxa traded in the marine aquarium trade (Militz, in press). This indicates that for many naturally rare taxa there will be no acceptable alternatives available to consumers. This is particularly true for taxa that exemplify unique behaviours, perform functional roles in aquaria, or have distinctive appearances (Hall et al., 2008). Demand for rare taxa with these attributes may be less easily shifted with consumer awareness campaigns and should be prioritised in future research assessing rarity-motivated exploitation for the aquarium trade.

Acknowledgements. This study was supported by the Australian Centre for International Agriculture Research (ACIAR) and the National Fisheries Authority (NFA) through ACIAR project FIS/2010/054 "Mariculture Development in New Ireland, Papua New Guinea" led by PCS at University of the Sunshine Coast. We are particularly grateful to H. Middleton and N. Piliman for assistance in the field and to the staff of the NFA Nago Island Mariculture and Research Facility for facilitating this research. We also thank the editor and two anonymous reviewers whose comments greatly improved earlier drafts of this publication.

\section{References}

Allen GR. The anemonefishes: their classification and biology, TFH Publications Inc, Neptune City, 1972

Bellwood DR, Hughes TP, Folke C, Nyström M. 2004. Confronting the coral reef crisis. Nature 429: 827-833.

Branch TA, Lobo AS, Purcell SW. 2013. Opportunistic exploitation: an overlooked pathway to extinction. Trends Ecol Evolut 28: 409-413.

Clark CW. 1973. The economics of overexploitation. Science 181: 630-634.

Cortesi F, Feeney WE, Ferrari MCO, Waldie PA, Phillips GAC, McClure EC, Sköld HN, Salzburger W, Marshall NJ, Cheney KL. 2015. Phenotypic plasticity confers multiple fitness benefits to a mimic. Curr Biol 25: 949-954.

Courchamp F, Angulo E, Rivalan P, Hall RJ, Signoret L, Bull L, Meinard Y. 2006. Rarity value and species extinction: the anthropogenic Allee effect. PLoS boil 4: e 415.

Dandava-Oli L, Sokou P, Wabnitz C. 2013. The marine aquarium trade in Papua New Guinea: historical context and current activities. SPC Fish. News lett 141: 37-40.

Dee LE, Horii SS, Thornhill DJ. 2014. Conservation and management of ornamental coral reef wildlife: successes, shortcomings, and future directions. Biol Cons 169: 225-237.

Drew JA, Allen GR, Kaufman L, Barber PH. 2008. Endemism and regional color and genetic differences in five putatively cosmopolitan reef fishes. Conserv Biol 22: 965-975.

Drew JA, Allen GR, Erdmann MV. 2010. Congruence between mitochondrial genes and color morphs in a coral reef fish: population variability in the Indo-Pacific damselfish Chrysiptera rex (Snyder, 1909). Coral Reefs 29: 439-444.

Dulvy NK, Sadovy Y, Reynolds JD. 2003. Extinction vulnerability in marine populations. Fish Fish 4: 25-64.

Eggert H, Lokina RB. 2007. Small-scale fishermen and risk preferences. Mar Resour Econ 21: 1-19.
Erdmann MV. 2001. Who's minding the reef? Corruption and enforcement in Indonesia. SPC Live Reef Fish Inf Bull 8: 19-20.

Fautin DG, Allen GR. Field guide to anemonefishes and their host sea anemones, revised edn, Perth, Western Australian Museum, 1997

Gordon HS. 1954. The economic theory of a common-property resource: the fishery. J Polit Econ 62: 124-142.

Grafton RQ, Kompas T, Hilborn RW. 2007. Economics of overexploitation revisited. Science 318: 1601.

Hall RJ, Milner-Gulland EJ, Courchamp F. 2008. Endangering the endangered: the effects of perceived rarity on species exploitation. Conserv Lett 1: 75-81.

Hamilton R, Green A, Almany J. 2009. Rapid ecological assessment: northern Bismarck Sea, Papua New Guinea. Technical report of survey conducted August 13 to September 7, 2006. Pacific Island Countries Report No. 1/09. South Brisbane, TNC.

Hothorn T, Zeileis A. 2015. Partykit: a molecular toolkit for recursive partitioning in R. J Mach Learn Res 16: 3905-3909.

Kahneman D, Tversky A. 1979. Prospect theory: an analysis of decision under risk. Econometrica 47: 263-291.

Kodric-Brown A. 1998. Sexual dichromatism and temporary color changes in the reproduction of fishes. Amer Zool 38: $70-81$.

Leal MC, Vaz MCM, Puga J, Rocha RJM, Brown C, Rosa R, Calado R. 2016. Marine ornamental fish imports in the European Union: an economic perspective. Fish Fish 17: 459-468.

Litsios G, Pearman PB, Lanterbecq D, Tolou N, Salamin N. 2014. The radiation of the clownfishes has two geographical replicates. J Biogeogr 41: 2140-2149.

Madduppa HH, Juterzenka K, Syakir M, Kockzius M. 2014. Socioeconomy of marine ornamental fishery and its impact on the population structure of the clown anemonefish Amphiprion ocellaris and its host anemones in Spermonde Archipelago, Indonesia. Ocean Coast Manage 100: 41-50.

Madduppa HH, Timm J, Kochzius M. 2018. Reduced genetic diversity in the clown anemonefish Amphiprion ocellaris in exploited reefs of Spermonde Archipelago, Indonesia. Front Mar Sci 5: 80 .

Militz TA. in press, Aquaculture in the aquarium industry, in: Lucas J. S., Southgate P.C., Tucker C.A. (Eds.), Aquaculture: farming aquatic animals and Plants, 3rd edition, Blackwell Publishing Ltd, https://www.wiley.com/en-au/Aquaculture $\% 3 \mathrm{~A}+$ Farming + Aquatic +Animals +and +Plants $\% 2 \mathrm{C}+3 \mathrm{rd}+$ Edition-p9781119230823.

Militz TA, Foale S. 2017. The 'Nemo Effect': perception and reality of Finding Nemo's impact on the marine aquarium fishery. Fish Fish 18, 596-606.

Militz TA, Kinch J, Southgate PC. 2015. Population demographics of Tridacna noae (Röding, 1798) in New Ireland, Papua New Guinea. J Shellfish Res 34: 329-335.

Militz TA, Kinch J, Foale S, Southgate PC. 2016a. Fish rejections in the marine aquarium trade: an initial case study raises concern for village-based fisheries. PLoS ONE 11: e0151624.

Militz TA., McCormick M.I., Schoeman D.S., Kinch J., Southgate P. C., 2016b, Frequency and distribution of melanistic morphs in coexisting population of nine anemonefish species in Papua New Guinea. Mar Biol 163, 200.

Militz TA, Foale S, Kinch J., Southgate PC. 2017. Consumer perspectives on theoretical certification schemes for the marine aquarium trade. Fish Res 193: 33-42.

Militz TA, Kinch, J, Southgate, PC. 2018a. Aquarium trade supplychain losses of marine invertebrates originating from Papua New Guinea. Environ Manage 61: 661-670. 
Militz TA, Kinch, J, Schoeman DS, Southgate PC. 2018b. Use of total allowable catch to regulate a selective marine aquarium fishery. Mar Pol 90: 160-167.

Murray JM, Watson GJ. 2014. A critical assessment of marine aquarist biodiversity data and commercial aquaculture: identifying gaps in culture initiatives to inform local fisheries managers. PLoS ONE 9: e105982.

Purcell SW, Mercier A, Conand C, Hamel J-F., Toral-Granda MV, Lovatelli A, Uthicke S. 2013. Sea cucumber fisheries: global analysis of stocks, management measures and drivers of overfishing. Fish Fish 14: 34-59.

R Core Team. 2017. R: a language and environment for statistical computing. R Foundation for Statistical Computing. https://www. R-project.org/.

Rhyne AL, Tlusty MF, Kaufman L. 2012a. Long-term trends of coral imports into the United States indicate future opportunities for ecosystem and societal benefits. Conserv Lett 5: 478-485.

Rhyne AL, Tlusty MF, Schofield PJ, Kaufman L, Morris JA Jr, Bruckner AW. 2012b. Revealing the appetite of the marine aquarium fish trade: the volume and biodiversity of fish imported into the United States. PLoS ONE 7: e35808.

Rosser AM, Mainka SA. 2002. Overexploitation and species extinctions. Conserv Biol 16: 584-586.
Saleem M, Islam F. 2008. Management of the aquarium fishery in the Republic of the Maldives. Proceedings of the 11th International Coral Reef Symposium, Ft. Lauderdale, 7-11 July 2008. Session 22: $1038-1042$.

Shuman CS, Hodgson G, Ambrose RF. 2005. Population impacts of collecting sea anemones and anemonefish for the marine aquarium trade in the Philippines. Coral Reefs 24: 564-573.

Slone TH, Orsak LJ, Malver O. 1997. A comparison of price, rarity and cost of butterfly specimens: implications for the insect trade and for habitat conservation. Ecol Econ 21: 77-85.

Stevenson TC, Tissot BN, Dierking J. 2011. Fisher behavior influences catch productivity and selectivity in West Hawaii's aquarium fishery. ICES J Mar Sci 68: 813-822.

Tea YK, Gill AC. 2016. Synchiropus sycorax, a new species of dragonet from the Philippines (Teleostei: Callionymidae). Zootaxa 4173: 85-93.

Vagelli AA. 2008. The unfortunate journey of Pterapogon kauderni: a remarkable apogonid endangered by the international ornamental fish trade, and its case in CITES. SPC Live Reef Fish Inf Bull 18: 17-28.

Wabnitz C, Taylor M, Green E, Razak T. From Ocean to Aquarium, UNEP-WCMC, Cambridge, 2003

Whitman EM, Cote IM, Reynolds JD. 2007. Ecological differences between hamlet (Hypoplectrus: Serranidae) colour morphs: between-morph variation in diet. J Fish Biol 71: 235-244.

Cite this article as: Militz TA, Foale S, Kinch J, Southgate PC. 2018. Natural rarity places clownfish colour morphs at risk of targeted and opportunistic exploitation in a marine aquarium fishery. Aquat. Living Resour. 31: 18 